\title{
Estrutura e padrões de distribuição espacial de Anadenanthera colubrina (Vell.) Brenan (Fabales: Fabaceae) presente no estrato regenerante em área de mata ciliar no Cariri Ocidental Paraibano
}

Jayane Karine Pereira de Araújo' ${ }^{1}$, Débora Souza dos Santos ${ }^{1}$, Rebeca Noemi de Oliveira Bezerra ${ }^{1}$, Jessica Sabrina Ovídio de Araújo $^{1}$, Micilene Silva de Brito ${ }^{1}$, Francisca Maria Barbosa ${ }^{2}$, Azenate Campos Gomes ${ }^{3}$, Rui Oliveira Macedo ${ }^{4}$, Alecksandra Vieira de Lacerda ${ }^{1}$,*

${ }^{1}$ Centro de Desenvolvimento Sustentável do Semiárido. Universidade Federal de Campina Grande. Sumé-PB, Brasil (CEP 58540-000).

${ }^{2}$ Instituto de Pesquisa em Fármacos e Medicamentos (IPeFarM). Universidade Federal da Paraíba. Campus Universitário. João Pessoa-PB, Brasil (CEP 58051-900). ${ }^{3}$ Programa de Pós-Gradução em Produtos Naturais e Sintéticos Bioativos. Universidade Federal da Paraíba. Campus Universitário. João Pessoa-PB, Brasil (CEP 58051-900).

${ }^{4}$ Universidade Federal da Paraíba. Centro de Ciências da Saúde. Departamento de Ciências Farmacêuticas. Campus Universitário. João Pessoa, PB (CEP 58037-275). *E-mail alecvieira@yahoo.com.br.

Resumo. A pesquisa teve como objetivo avaliar dados da estrutura fitossociológica associado aos padrões de distribuição espacial de jovens regenerantes do angico Anadenanthera colubrina (Vell.) Brenan presentes em área ciliar de Caatinga no Semiárido paraibano. O levantamento realizou-se ao longo do Riacho da Umburana ( $7^{\circ} 45^{\prime} 15,3^{\prime \prime} \mathrm{S}$ e $36^{\circ} 58^{\prime} 01,6^{\prime \prime}$ W; $571 \mathrm{~m}$ de altitude). Foram dispostas para a pesquisa do banco de jovens 51 parcelas de $1 \times 1 \mathrm{~m}$. Nas parcelas inventariadas foram amostradas 30 espécies distribuídas em 23 gêneros e 12 famílias botânicas, além de quatro espécies indeterminadas. Inserida nesta riqueza florística, A. colubrina ficou representada por 19 indivíduos. A Frequência Absoluta (FR) desta espécie foi de 23,53\%. A maioria das parcelas (oito) deteve apenas um indivíduo, ficando as demais variando de dois a quatro. Para os dados de classes de altura e diâmetro dos indivíduos amostrados observou-se um comportamento similar para as duas variáveis estudadas, ou seja, ocorreu uma maior distribuição de indivíduos nas classes de menor valor. Portanto, os dados gerados definem relevantes subsídios para os campos da biologia da conservação de A. colubrina e para as estratégias de recuperação de ambientes ribeirinhos degradados no Semiárido brasileiro.

Palavras-chave: Regeneração natural; Dinâmica populacional; Região semiárida.
Recebido:

$29 / 01 / 2018$

Aceito:

$21 / 04 / 2018$

Publicado:

30/04/2018

Acesso aberto

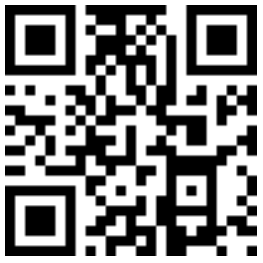

ORCID

(1) 0000-0002-3724-643X Jayane Karine Pereira de Araújo 
Abstract. Structure and pattern of spatial distribution of Anadenanthera colubrina (Vell.) Brenan (Fabales: Fabaceae) in the regenerating stratum of a riparian forest area in the Cariri Ocidental Microregion of Paraíba State, Brazil. This study aimed to evaluate the data on the phytosociological structure associated with the spatial distribution patterns of young regenerating plants of angico Anadenanthera colubrina (Vell.) Brenan in a riparian area of Caatinga in the semi-arid region of Paraíba State, Brazil. The survey was carried out along the Umburana stream $\left(7^{\circ} 45^{\prime} 15.3^{\prime \prime} \mathrm{S}\right.$ and $36^{\circ} 58^{\prime} 01.6^{\prime \prime} \mathrm{W} ; 571 \mathrm{~m}$ of altitude). A total of 51 plots ( $1 \times 1 \mathrm{~m})$ were arranged for the survey of the bank of seedlings. In the 51 plots, in addition to four indeterminate species, 30 species were sampled, distributed in 23 genera and 12 botanical families. Inserted in this floristic richness, A. colubrina was represented by 19 individuals. This species had an Absolute Frequency (FR) of $23.53 \%$. Most of the plots (eight) held only one individual and the other ones held from two to four individuals. For the data relating to classes of height and diameter of the sampled individuals, similar behavior was observed for both studied variables, i.e., there was a greater distribution of individuals in the classes of lower value. Therefore, the data generated in this study give relevant support in the fields of conservation biology of $A$. colubrina and in the development of strategies for the recovery of degraded riparian environments in the Brazilian semi-arid region.

Keywords: Natural regeneration; Population dynamics; Semi-arid region.

\section{Introdução}

A Região Semiárida Brasileira se define pela heterogeneidade das condições naturais como o clima, solo, topografia e vegetação. Segundo Mendes (1986), o traço mais marcante dessa região é o clima, principalmente pela existência de um regime pluviométrico que delimita duas estações bem distintas: uma curta estação chuvosa de 3 a 5 meses, denominada de inverno e uma longa estação seca, chamada de verão, com duração de 7 a 9 meses. Segundo o MMA (2010), o Bioma Caatinga é predominante nessa região, e ocupa cerca de $11 \%$ do território brasileiro $\left(844.453 \mathrm{~km}^{2}\right)$. Este bioma é considerado exclusivamente brasileiro, entretanto, é o ecossistema menos conhecido da América do Sul, tendo em vista, o pequeno número de pesquisas realizadas

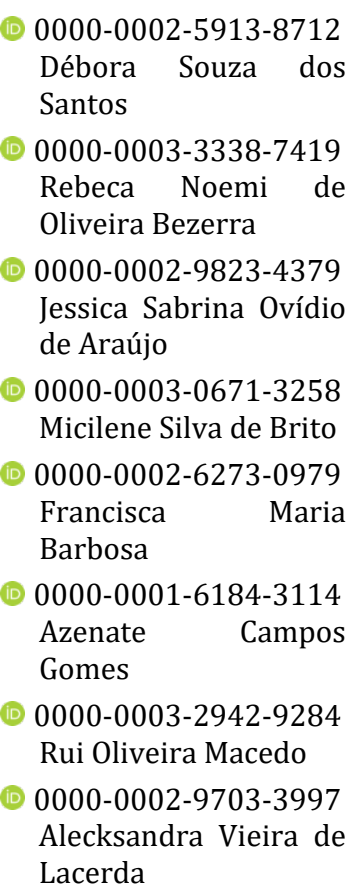

Lacerda 
peculiaridades, devido à carência de pesquisas detalhadas na região. Como exemplo disso tem-se o potencial biológico das áreas ciliares de Caatinga (Lacerda et al., 2010).

As matas ciliares são consideradas áreas de preservação permanente (APPs) protegida pela Lei $\mathrm{n}$ 12.651/2012 do código Florestal Brasileiro (Brasil, 2012). Esses ambientes são extremamente importantes no que tange aos seus aspectos funcionais, ao passo que, são responsáveis pelo equilibro ecológico dos ecossistemas, agindo como corredor de fluxo gênico da fauna e flora a partir do trânsito de espécies e disseminação através da água, vento e animais. Estes ambientes se destacam ainda por sua importância como protetores e mantenedores da qualidade da água e do solo.

Nas faixas ciliares existem populações com grande potencial, expresso este nas escalas ambiental, econômica e social. A população de Anadenanthera colubrina (Vell.) Brenan assim se define dentro das escalas referenciadas. Esta espécie tem sua ocorrência em todos os estados do Nordeste Brasileiro e apresenta-se principalmente em regiões de clima semiárido, além de outros estados do Sudeste e do Centro-oeste do Brasil, ocorrendo principalmente nas regiões onde as matas se configuram como mais secas.

Conhecida popularmente como angico ou angico branco é uma espécie da Família Fabaceae (Lima, 2011), apresentando-se esta com grande necessidade de exposição solar e característica caducifólia (Guimarães, 2009). É geralmente de médio e grade porte, dotada de copa larga e espalhada e galhos arqueados, permitindo a passagem de grande quantidade de luz. Nas áreas de Caatinga, apresenta altura variando entre 3 a $15 \mathrm{~m}$, além de apresentar queda das folhas durante a estação seca. 0 caule apresenta-se com diâmetro de 40 a $90 \mathrm{~cm}$, geralmente ereto ou pouco tortuoso, revestido por uma casca que varia de lisa e clara até rugosa ou muito fissurada e escura. Os caules normalmente apresentam-se com numerosos espinhos e as folhas são bicompostas e alternas, com até 30 pares de folíolos opostos, sendo cada folíolo composto de vários folíolos opostos. As flores se caracterizam como pequenas, amarelo-esbranquiçadas e reunidas em capítulos globulosos axilares terminais (Azevedo et al., 2014).

Registra-se também o uso dessa espécie na medicina popular (Almeida e Albuquerque, 2002), tendo efeito terapêutico (Weber et al, 2011), potencial antioxidante e antimicrobiano (Castro, 2011), bem como o uso do seu extrato rico em taninos no curtimento de peles caprinas (Lima et al., 2014) e extração de sua madeira para atividades de construção rural e civil, fabricação de móveis rústicos e com fins energéticos (Barbosa et al., 2011), sendo utilizada também na confecção de linhas, mourões e estacas para cercas (Lima, 2011), tabuado, tacos, desdobro, obras internas, ripas, implementos, embalagens, construção naval (Campos Filho e Sartorelli, 2015).

Diante da sua importância como recurso e de seu amplo uso nos mais diversos setores, a pesquisa objetivou avaliar dados da estrutura fitossociológica associada aos padrões de distribuição espacial de jovens regenerantes do angico (Anadenanthera colubrina (Vell.) Brenan) presentes em área ciliar de Caatinga no Semiárido paraibano.

\section{Material e métodos}

\section{Área de estudo}

O trabalho foi desenvolvido no Cariri paraibano, o qual ocupa uma área de $11.233 \mathrm{~km}^{2}$, e se divide em duas microrregiões, Cariri Ocidental e Cariri Oriental, e é constituído por 29 municípios. Segundo o censo de 2010, 
possui uma população de 185.235 , sendo 121.531 pertencentes ao Cariri Ocidental e 63.704 ao Cariri Oriental (IBGE, 2010).

o Cariri Paraibano é caracterizado pela mudança da passagem da estação chuvosa para a seca e viceversa, e pelo regime interanual, cuja irregularidade ou variabilidade ano a ano dos totais pluviométricos tem uma distribuição temporal muito dispersa (Alves et al., 2009). Segundo a classificação climática de Köppen (1900), o clima da região enquadra-se no tipo BSh, denominado semiárido, caracterizado por insuficiência e irregularidade das precipitações pluviais, as quais se concentram em três meses do ano, e ocorrência de temperaturas elevadas.
O trabalho de campo foi executado no município de Sumé localizado na microrregião do Cariri Ocidental entre as coordenadas geográficas $07^{\circ} 40^{\prime} 18^{\prime \prime} \mathrm{S}$ e $36^{\circ} 52^{\prime} 48^{\prime \prime} \mathrm{W}$.

A área ciliar selecionada no município esta localizada em um remanescente que se apresenta em bom estágio de conservação. Assim, foi amostrado um trecho no Riacho da Umburana (Figura 1), localizado na propriedade rural Fazenda Nova, nas coordenadas geográficas de $7^{\circ} 45^{\prime} 15,3^{\prime \prime} \mathrm{S}$ e $36^{\circ} 58^{\prime} 01,6^{\prime \prime} \mathrm{W}$, a $571 \mathrm{~m}$ de altitude. Esse curso d'água nasce no Sítio Boa Esperança, no Município de Monteiro-PB e desemboca no Açude Jatobá, em SuméPB.

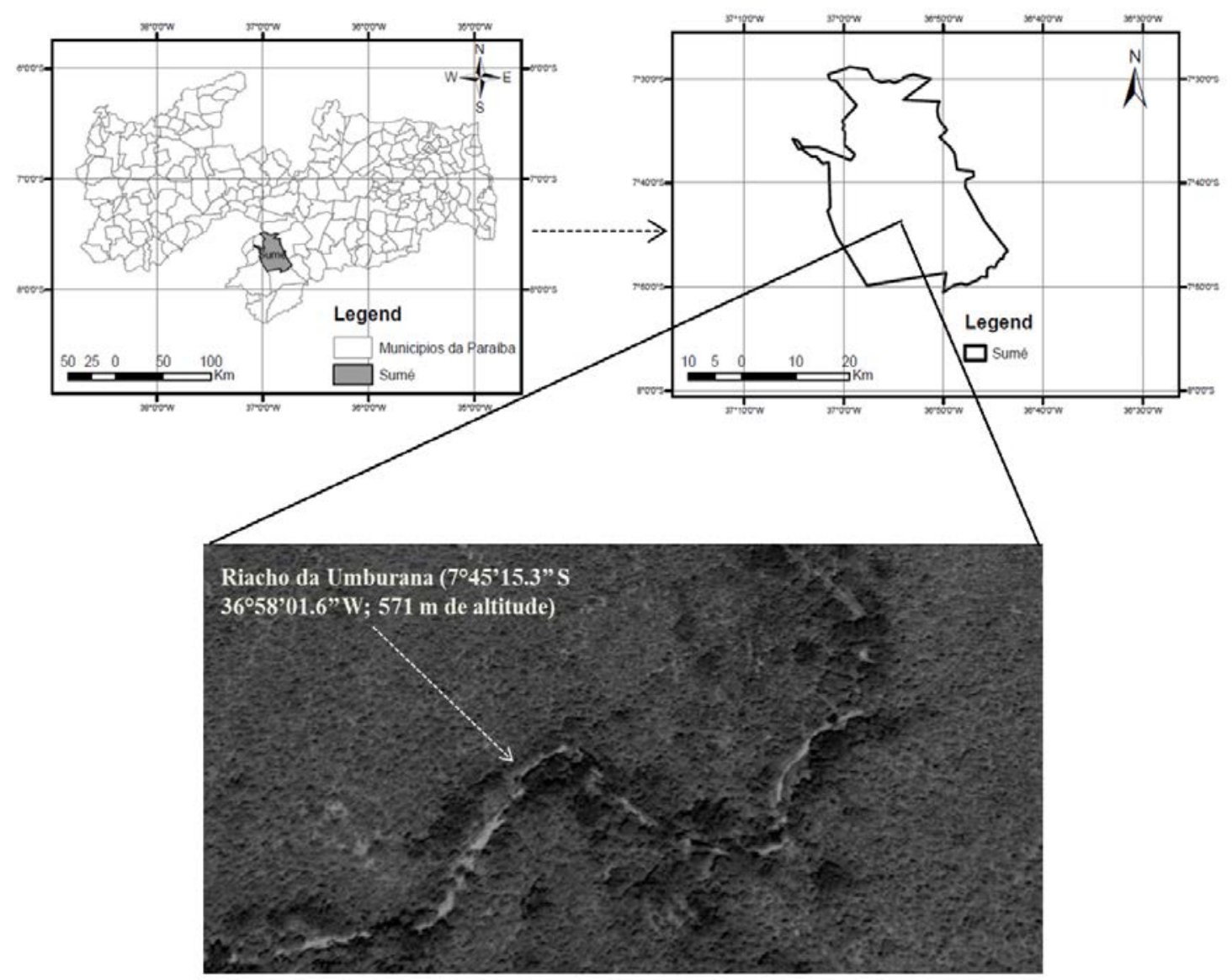

Figura 1. Localização do Riacho da Umburana no Município de Sumé, Semiárido da Paraíba, Brasil (Farias et al., 2017). 


\section{Coleta e análise dos dados}

O banco de indivíduos jovens de A. colubrina foi analisado mediante a implantação de 51 parcelas de $1 \times 1 \mathrm{~m}$. Todos os indivíduos jovens lenhosos presentes nestas parcelas, com altura $\geq$ $0,01 \mathrm{~m}$ e DNS $<3 \mathrm{~cm}$, foram etiquetados e numerados, medindo-se os valores de altura total com uma régua graduada e anotando-se todas as informações observadas em campo. 0 inventário foi realizado durante o final do período chuvoso (julho/2012).

$\mathrm{Na}$ avaliação da estrutura vertical da regeneração natural foram definidas classes de tamanho (classes de regeneração) e para análise estrutural da vegetação utilizou-se os seguintes parâmetros: frequência, densidade e classes de altura e diâmetro da regeneração natural (Volpato, 1994).

\section{Resultados e discussão}

Nas 51 parcelas inventariadas
foram amostradas 30 espécies distribuídas em 23 gêneros e 12 famílias botânicas, além de quatro espécies indeterminadas. Inserida nesta riqueza florística $A$. colubrina ficou representada por 19 indivíduos. Barbosa (2008), trabalhando com o estrato regenerante registrou em uma área ciliar no Cariri paraibano 14 e 15 indivíduos desta espécie em dois monitoramentos executados ambos no período chuvoso.

A frequência absoluta (FR) desta espécie foi de $23,53 \%$, encontrando-se distribuída em 12 do total das 51 parcelas amostradas. A maioria das parcelas (oito) deteve apenas um indivíduo, ficando as demais variando de dois a quatro (Figura 2).

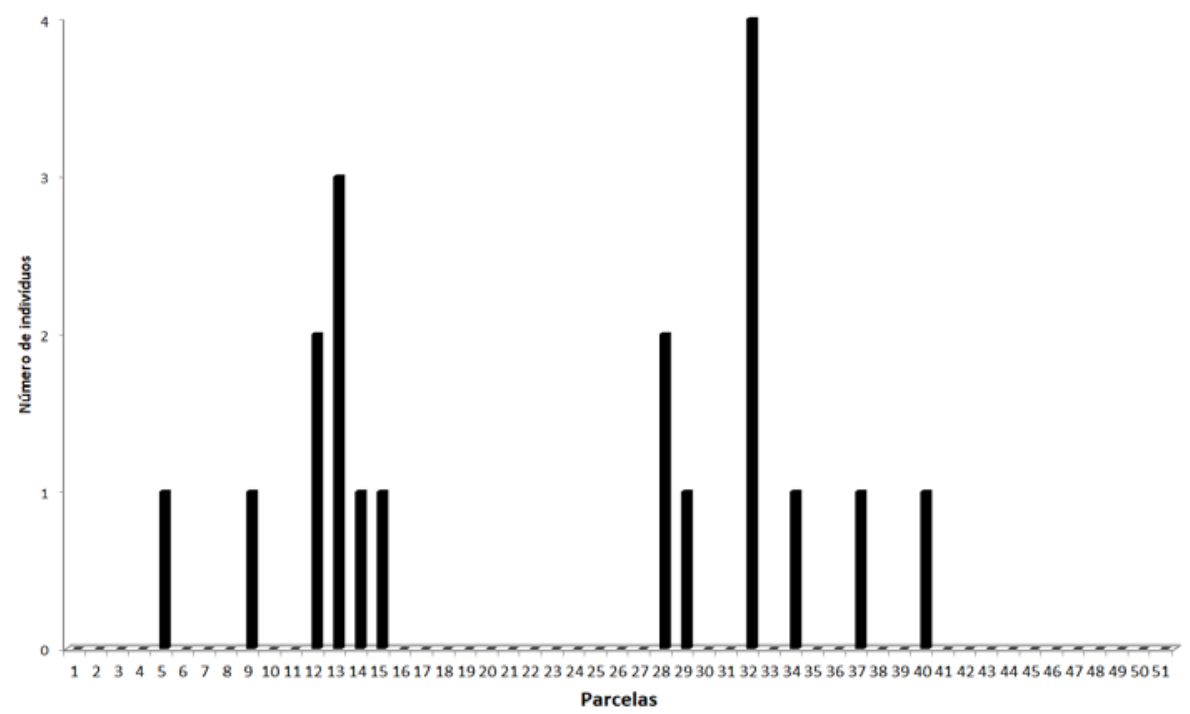

Figura 2. Distribuição do número de indivíduos de $A$. colubrina nas parcelas implantadas para amostragem do estrato regenerante em área ribeirinha do riacho da Umburana no município de Sumé, Cariri paraibano.

Nesta mesma área, Gomes (2013) realizou o estudo com o componente adulto e registrou 4.022 indivíduos vivos e 151 mortos em pé. Os indivíduos vivos se distribuíram em 44 espécies, 32 gêneros e 17 famílias. Desse total, $A$. colubrina ficou representada por 134 indivíduos, área basal $(\mathrm{AB})$ de 1,412 $\mathrm{m}^{2}$, densidade absoluta (DA) 131 ind.ha $^{-1}$, densidade relativa (DR) 3,21\%, frequência absoluta (FA) 84,30\%, frequência relativa (FR) 5,71\%, dominância absoluta 1,385 $\mathrm{m}^{2} / \mathrm{ha}$, dominância relativa $15,8 \%$, valor de 
cobertura 10,1, e ocupou assim, a sétima posição no valor de importância (15,8\%). Comparando os valores de frequência absoluta dos indivíduos adultos $(84,30 \%)$ com os registrado neste estudo $(23,53 \%)$ observou-se que a espécie embora bem distribuída no estrato adulto não apresenta o mesmo perfil no estrato regenerante $o$ que pode comprometer a reposição da mesma em uma escala de médio e longo prazo. De acordo com Paes et al. (2006) a exploração das espécies fazem com que as mesmas tendam a desaparecer da paisagem do Semiárido devido a exploração desordenada, a falta de práticas adequadas de manejo ou de uma política de reflorestamento que vise à reposição das árvores exploradas está levando ao esgotamento dos recursos vegetais.

Para os dados de classes de altura e diâmetro (Figuras 3 e 4) dos indivíduos amostrados na vegetação ribeirinha do riacho da Umburana, observou-se um comportamento similar para as duas variáveis estudadas, ou seja, ocorreu uma maior distribuição de indivíduos nas classes de menor valor. Para a altura $52,63 \%$ dos indivíduos se concentraram na menor classe $(0,01$ a $0,50 \mathrm{~m})$. Analisando os dados de diâmetro ao nível do solo, observou-se o mesmo padrão, com o maior número de indivíduos na primeira classe $(0,01$ a $0,50 \mathrm{~cm})$, chegando o percentual de $57,89 \%$ do total de indivíduos registrados.

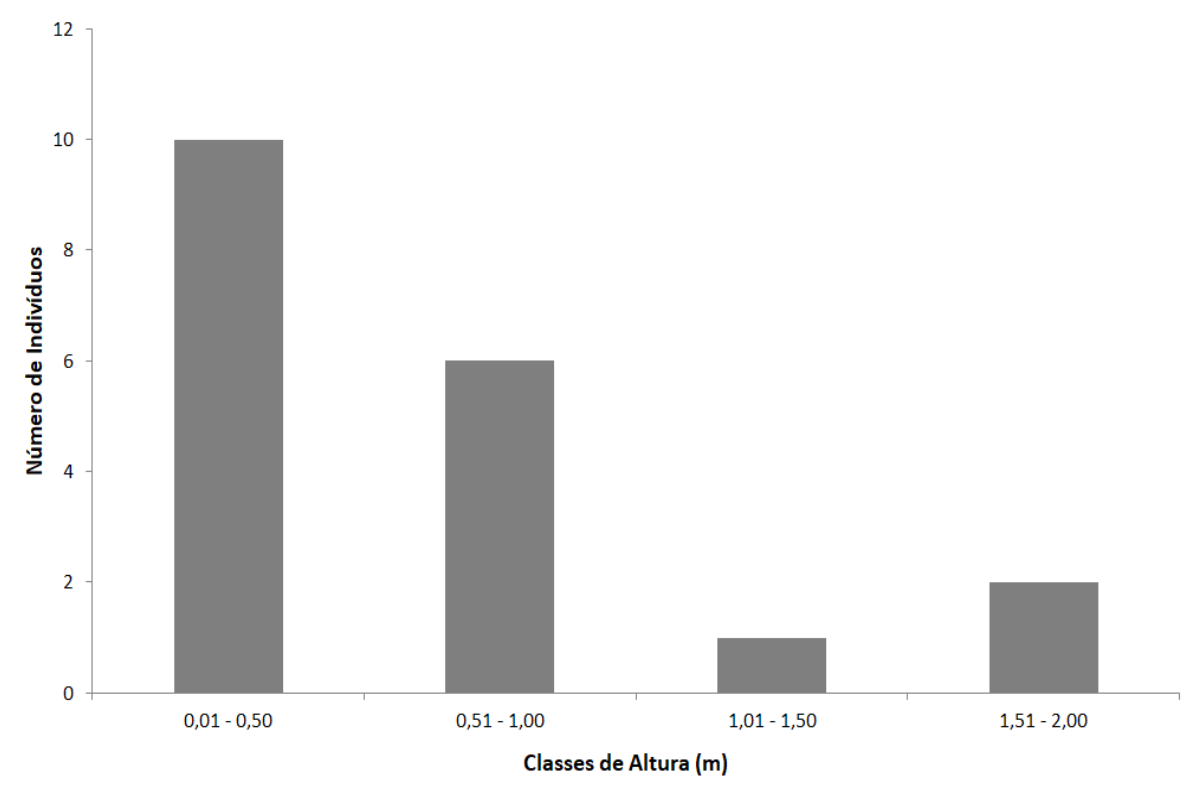

Figura 3. Distribuição por classe de altura dos indivíduos de A. colubrina registrados nas parcelas implantadas para amostragem do estrato regenerante em área ribeirinha do riacho da Umburana no Município de Sumé, Cariri paraibano.

Barbosa (2008) em seu estudo com o estrato regenerante também evidenciou o mesmo comportamento. Colaborando ainda com esta discussão, autores como Fenner (1987) colocam que nos trópicos, as espécies arbustivoarbóreas normalmente apresentam curvas de sobrevivência caracterizadas por um número grande de indivíduos nas fases iniciais de vida, com decréscimo à medida que a idade aumenta. Assim, tem-se ratificado nos sistemas naturais do semiárido comportamento de populações como anteriormente referenciado pelo último autor. 


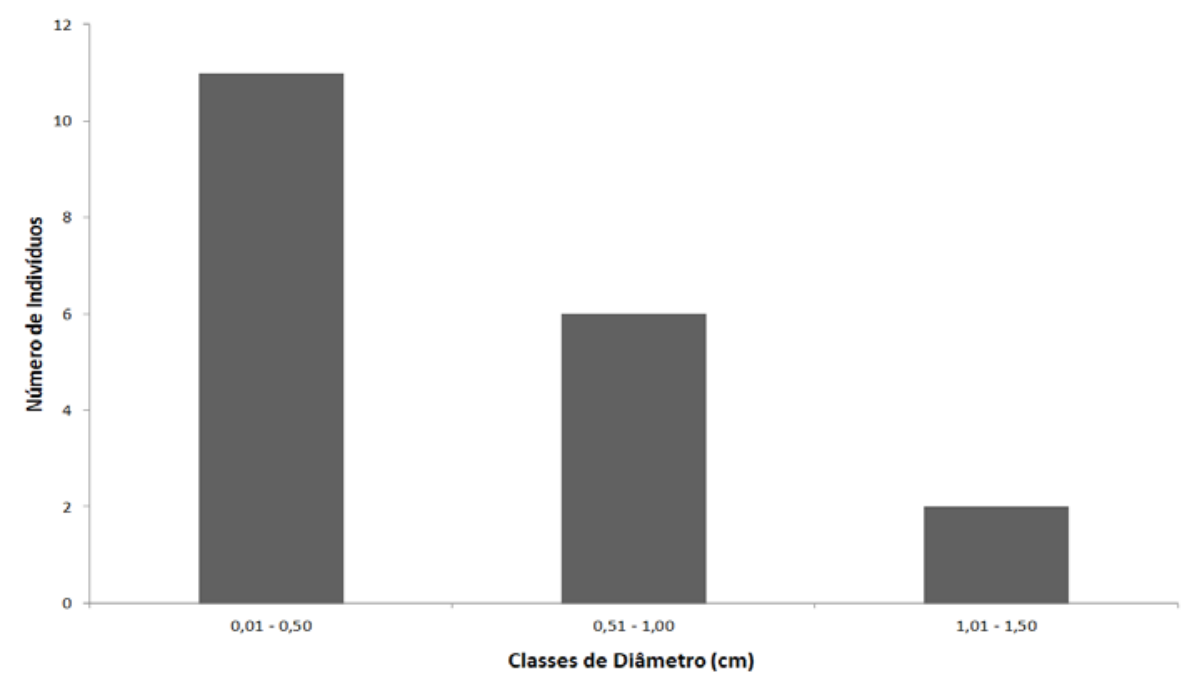

Figura 4. Distribuição por classe de diâmetro dos indivíduos de $A$. colubrina registrados nas parcelas implantadas para amostragem do estrato regenerante em área ribeirinha do Riacho da Umburana no Município de Sumé, Cariri paraibano.

\section{Conclusões}

Portanto, a pesquisa forneceu subsídios para o entendimento da dinâmica de $A$. colubrina a qual apresenta elevado valor ambiental, social e econômico demonstrando assim a importância do manejo para garantir a renovação dos sistemas naturais no Semiárido brasileiro.

\section{Agradecimentos}

Ao $\mathrm{CNPq}$ pelo financiamento da pesquisa, à família Mayer, proprietária da Fazenda Nova, e aos integrantes do Laboratório de Ecologia e Botânica.

\section{Declaração de conflito de interesses}

Os autores declaram não haver conflito de interesses.

\section{Referências}

Almeida, C. F. C. B. R; Albuquerque, U. P. Uso e conservação de plantas e animais medicinais no Estado de Pernambuco (Nordeste do Brasil): um estudo de caso. Interciência, v. 27, p. 276-285, 2002.
Alves, J. J. A.; Araújo, M. A.; Nascimento, S. S. Degradação da caatinga: uma investigação ecogeográfica. Revista Caatinga, v. 22, n. 3, p. 126-135, 2009. Disponível em: <https://periodicos.ufersa.edu.br/index.php /caatinga/article/view/560/645>. Acesso em: 29 jan. 2018.

Azevedo, C. F.; Bruno, R. L. A.; Quirino, Z. G. M. Manual de frutos, sementes e plântulas de espécies arbóreas da Caatinga. Brasília: Kiron, 2014.

Barbosa, F. M. Estudo do potencial de regeneração natural: uma análise da chuva de sementes, banco de sementes e do estrato regenerante da vegetação ciliar na Bacia Hidrográfica do Rio Taperoá, semi-árido paraibano, Brasil. São Carlos: Universidade Federal de São Carlos, 2008. (Tese de Doutorado).

Barbosa, F. M.; Lacerda, A. V.; Barbosa, M. R.V. Flora e estrutura em áreas de extração de cascas de angico vermelho (Anadenanthera colubrina (Vell.) Brenan) no semiárido paraibano, Brasil. Anais do X Congresso de Ecologia do Brasil, São Lourenço, 2011.

Brasil. Lei no 12.651, de 25 de maio de 2012. Dispõe sobre a proteção da vegetação nativa; altera as Leis $\mathrm{n}^{\text {os }} 6.938$, de 31 de agosto de 1981, 9.393, de 19 de dezembro de 1996, e 11.428, de 22 de dezembro de 2006; revoga as Leis nos 4.771 , de 15 de setembro 
de 1965 , e 7.754 , de 14 de abril de 1989 , e a Medida Provisória no 2.166-67, de 24 de agosto de 2001; e dá outras providências. Disponível em: <http://www.planalto. gov.br/ccivil_03/_Ato2011-2014/2012/Lei/ L12651.htm>. Acesso em: 07 jan. 2013.

Campos Filho, E. M.; Sartorelli, P. A. R. Guia de árvores com valor econômico. São Paulo: Agroicone, 2015.

Castro, V. T. N. A. Atividade antimicrobiana e antioxidante de Anadenanthera colubrina (Vell.) Brenan e incorporação em gel dermatológico. Recife: Universidade Federal de Pernambuco, 2011. (Dissertação de mestrado).

Farias, R. C.; Lacerda, A. V.; Gomes, A. C.; Barbosa, F. M.; Dornelas, C. S. M. Riqueza florística em uma área ciliar de caatinga no Cariri Ocidental da Paraíba, Brasil. Revista Brasileira de Gestão Ambiental e Sustentabilidade, v. 4, n. 7, p. 109-118, 2017. https://doi.org/10.21438/rbgas.040711

Fenner, M. Seedlings. The New Phytologist, v. 106, p. 35-47, 1987.

Gomes, A. C. Estudo da estrutura e dinâmica do componente arbóreo-arbustivo em área ciliar de Caatinga: subsídios para a recuperação de áreas degradadas e suporte para a implantação de Sistemas Agroflorestais no Semiárido Paraibano. Sumé: Universidade Federal de Campina Grande, 2013. (Monografia de gradução).

Guimarães, R. C. Anatomia do lenho de Anadenanthera colubrina (Vell.) Brenan em diferentes fitofisionomias da Floresta Atlântica no Estado do Rio de Janeiro, Ilha Grande e Itatiaia. Rio de Janeiro: Instituto de Pesquisas Jardim Botânico do Rio de Janeiro, 2009. (Dissertação de Mestrado).

IBGE - Instituto Brasileiro de Geografia e Estatística. Censo demográfico 2010. Disponível em: <http://www.ibge.gov.br/ cidadesat/topwindow.htm?1>. Acesso em: 25 jun. 2017.

Köppen, W. Versuch einer Klassifikation der Klimate, vorzugsweise nach ihren Beziehungen zur Pflanzenwelt. Geographische Zeitschrift, v. 6, n. 12, p.657-679, 1900. Disponível em: <http://www.jstor.org/stable/27803939>. Acesso em: 29 jan. 2018.

Lacerda, A. V.; Barbosa, F. M.; Soares, J. J.; Barbosa, M. R. V. Flora arbustiva-arbórea de três áreas ribeirinhas no semiárido paraibano, Brasil. Biota Neotropica, v. 10, n. 4, p. 275-284, 2010. https://doi.org/10.1590/ S1676-06032010000400032

Lima, B. G. Caatinga: espécies lenhosas e herbáceas. Mossoró: EdUfersa, 2011.

Lima, C. R.; Paes, J. B.; Lima, V. L.; Delgado, M. F. F.; Lima, R. A. Potencialidade dos extratos tânicos de três espécies florestais no curtimento de peles caprinas. Revista Brasileira de Engenharia Agrícola e Ambiental, v. 18, n. 11, p. 1192-1197, 2014. https://doi.org/10.1590/1807-1929/ agriambi.v18n11p1192-1197

Mendes, B. V. Alternativas tecnológicas para a agropecuária do semiárido. São Paulo: Nobel, 1986.

MMA - Ministério do Meio Ambiente. Monitoramento por satélite do desmatamento no Bioma Caatinga. Brasília: MMA, 2010.

Paes, J. B.; Diniz, C. E. F.; Marinho, I. V.; Lima, C. R. Avaliação do potencial tanífero de seis espécies florestais de ocorrência no semiárido brasileiro. Cerne, v. 12, n. 3, p. 232-238, 2006. Disponível em: <http://www.cerne. ufla.br/site/index.php/CERNE/article/view/ 385/328>. Acesso em: 29 jan. 2018.

Volpato, M. M. L. Regeneração natural em uma floresta secundária no Domínio de Mata Atlântica: uma análise fitossociológica. Viçosa: Universidade Federal de Viçosa, 1994. (Dissertação de Mestrado).

Weber, C. R.; Soarez, C. M. L.; Lopes, A. B. D.; Nascimento, M. S.; Ximenes, E. C. P. A. Anadenanthera colubrina: um estudo do potencial terapêutico. Revista Brasileira de Farmácia, v. 92, p. 235-244, 2011.

Informação da Licença: Este é um artigo Open Access distribuído sob os termos da Licença Creative Commons Attribution, que permite uso irrestrito, distribuição e reprodução em qualquer meio, desde que a obra original seja devidamente citada. 